though their colleagues verified their observations. Here is the great enigma of the history of telescopic astronomy. We need to learn what it was about Galileo, Cassini or Herschel that made them right. But before we can find the answer to that question, we need to know how Schia- parelli and many of his contemporaries could be so wrong. Sheehan's account goes a long way towards answering that question.

Albert Van Helden is a Professor in the Department of History, Rice University, PO Box 1892 Houston, Texas 77251, USA.

\section{On the move}

\section{Martin Rudwick}

\section{Drifting Continents and Shifting Theories: The Modern Revolution In Geology and Scientific Change. By H. E. LeGrand. Cambridge University Press: 1988. Pp.313. Hbk £30, \$49.50; pbk £10.95, $\$ 16.95$.}

THE image of 'revolution' has been an integral part of the self-understanding of the modern Earth sciences ever since the theory that is now termed plate tectonics gained wide acceptance in the 1960s. One of the first major post-war volumes to favour crustal mobilism, the symposium on Continental Drift edited by Runcorn, appeared in 1962, the same year as Kuhn's Structure of Scientific Revolutions. The enthusiastic adoption of the kuhnian language of paradigms and revolutions by many Earth scientists in the later 1960s was no coincidence. It reflected a widespread sense of living through a period of dramatic conceptual change, which promised to transcend earlier disciplinary divisions and to make a unified 'Earth science' an attainable goal. Kuhn's model of scientific change, itself representing a dramatic break with orthodox philosophy of science, seemed tailor-made for Earth scientists. The use of such philosophical models to interpret the origin and development of plate tectonic theory is thus a tradition that stems from within the science itself.

Hallam's Revolution in the Earth Sciences, which was published in 1973 almost before the dust had settled, was one of the first - and one of the best - of a distinctive genre of historico-philosophical analyses by practising Earth scientists. 'Practitioner histories' have their limitations, however, because the professionalism of their treatment of the technical issues is inevitably offset by a less than professional acquaintance with the wider issues that any general model of scientific change entails. 'Participant histories', such as Menard's delightful Ocean of Truth (1986), are also invaluable; but like any other primary source they need to be treated as raw material for historical interpretation, rather than as unproblematical accounts of 'how it actually was'.

Homer LeGrand's new treatment of the history of 'Drift' - as he usefully terms all theories of crustal mobilism - is different, in that the author's professional affil- iations are with the burgeoning field of science studies. Whatever his book may lack in the way of a participant's vivid recall of events, or a practitioner's tacit feeling for the science, is amply compensated by its sophisticated and up-to-date treatment of the historical, sociological and philosophical issues. As the title implies, the book is concerned with shifts in theories as well as continents.

Readers who like their history of science penny-plain are well served by a beautifully clear and concise narrative. This is grounded in a substantial bibliography; it is illustrated by reproductions of significant diagrams; and it shows an admirable mastery of the technical issues. The narrative is far less detailed than, for example, Glen's Road to Jaramillo (1982), but it covers a far wider field, and it is much better balanced than any comparable account. The book avoids the 'precursoritis' that turns Alfred Wegener into a neglected prophet or a retrospective hero. It also avoids the provincialism of some other histories of plate tectonics, which distort the picture by concentrating on those who constructed the theory in the form that became orthodoxy in the $1970 \mathrm{~s}$.

An early chapter sketches the latenineteenth-century background of highlevel theoretical debate between 'permanentists' and 'contractionists'; the contrast in scientific style between Europeans and Americans, which became so striking when Drift theories were revived in the $1960 \mathrm{~s}$, was clearly apparent even at this early stage. Global theorizing was an established and respectable tradition in German-language geology, and LeGrand neatly summarizes the lively debate that Wegener's Origin of Continents and Oceans (1915) evoked as soon as the First World War was over, not only in continental Europe but also in Britain. Even more importantly, he documents the unbroken tradition that linked those debates of the 1920 s with the revival of Drift theorizing in the $1950 \mathrm{~s}$. The very possibility of Drift was indeed rejected vehemently by most of the leaders of the North American scientific community during this period, as it continued to be by Soviet scientists even through the 1970s. But for the Europeans, and still more for geologists in the Southern Hemisphere, various forms of Drift, progressively improved from Wegener's original formulation, remained a live option, albeit a minority position, that was continually under review.

Having established that vital continuity,
LeGrand shows how the crucial new input from the physical scientists in the $1950 \mathrm{~s}$, namely in the technique of palaeomagnetism and the theory of polar wandering, created an increasingly favourable climate for Drift theorizing among land-based geologists and geophysicists. Contrary to subsequent myths, this dramatic revival in the fortunes of Drift theorizing took place before the burgeoning breed of oceangoing scientists began to apply their mass of new data to the interpretation of global tectonics. The rest, as journalists are fond of saying, is history. However, LeGrand continues his narrative with an account of the emergence of plate tectonics from preexisting forms of Drift theory. Notwithstanding his own title, he interprets this convincingly as a story of continuous conceptual evolution rather than as a revolutionary break with the past. Finally he traces the precipitate conversion of the North American scientific community, and, to avoid too triumphalist a conclusion, notes continuing pockets of sceptical resistance elsewhere in the world.

Readers who want a tuppence-coloured version of this history get it, at no extra cost, in the form of what LeGrand terms "Voice-Overs" at the end of each chapter. These are brief commentaries on the foregoing narrative, reflecting on its compatibility - or more often, incompatibility with the main theories of scientific change discussed among philosophers of science in the past quarter-century. The 'paradigms' of Kuhn and the 'research programmes' of Lakatos are given respectful consideration, but are rejected as incompatible with this particular example of scientific change. LeGrand has more sympathy with Laudan's model of 'research traditions', although in my opinion his narrative does not lend it much better support than the others. The 'interest model' of the Edinburgh school of science studies, with its emphasis on the constitutive role of the socio-economic context of scientific work, is effectively applied, for example to the interpretation of the rise of ocean-going Earth science in relation to the needs of the United States Navy in the era of the Cold War. But in my view, what LeGrand terms the 'internal struggle' model, now associated particularly with Latour and other French analysts of science, is easily the best supported by his narrative.

This is a book that deserves a wide readership among Earth scientists of all stripes, as well as among historians, sociologists and philosophers of science. It gives the best brief narrative there is of the origins of plate tectonic theory; and it combines that with a thought-provoking and undogmatic evaluation of the story as a notable episode of conceptual change in modern science.

Martin Rudwick is Professor of History of Science at the University of California San Diego, La Jolla, California, 92093, USA. 